Mathias Wirth*

\title{
Trostlose Eschatologie?
}

\section{Zu einer unerledigten Kontroverse über Versöhnung in der neueren Dogmatik}

DOI $10.1515 /$ nzsth-2016-0016

Zusammenfassung: Als eschatologische Konsequenz wirksamer Anerkennung der Freiheit des Menschen durch Gott hat Karl-Heinz Menke mehrfach ein Szenario beschrieben, bei dem Erlösung an die Bedingung eines Verzeihungsaktes des „Opfers“ gegenüber seinem „Peiniger“ gebunden ist, weil Gott nicht am „Opfer“ vorbei eschatologischen Frieden kreieren könne. Menkes Plädoyer für eine offene Geschichte bedingt einen eschatologischen Interaktionismus, der dem „Opfer“ die Leistung abverlangt, verzeihen zu müssen. Dies hat in einer Kontroverse aus 2009 Bernd Oberdorfer scharf kritisiert und erinnert an die Option der Unmöglichkeit des Verzeihens. Bei Menke, so Oberdorfer, bleibe das „Opfer“ notorisch Teil der Rechnung des „Täters“, wenn das Reich Gottes erst dann vollendet ist, wenn auch das letzte „Opfer“ seinem „Täter“ die Hand reicht. Insgesamt votiert Menke für das Modell der Heilsungewissheit in der Eschatologie, die bei ihm umso fulminanter ausfällt, als er das „alles in allem“ (1 Kor 15,28) an die Fragilität dessen bindet, was Menschen vermögen. Das ebenfalls in der christlichen Theologie prominent vertretene Modell der Heilsgewissheit in der Eschatologie hält den neuen Himmel und die neue Erde nicht für eine bloße Eventualität, sondern für eine anbrechende Faktualität. Hier fungiert der Morgen von Ostern nicht als Utopie, sondern als Hoffnungsbild, das keineswegs die Verzeihung des Unverzeihlichen voraussetzt. Auch der auferstandene Gekreuzigte reicht seinen Schächern nicht die Hand. Im Sieg des Lebens über den Tod beginnt etwas schlechthin Neues, nach dem sich „Täter“ und „Opfer“ sehnen können.

Schlüsselwörter: Eschatologischer Interaktionismus, Heilsgewissheit, Infernalismus, Täter-Opfer-Verhältnis, Versöhnung

Summary: As an eschatological consequence of the effective recognition of people's freedom through God, Karl-Heinz Menke often described a scenario

*Korrespondenzautor: Dr. des., Dipl. Theol. Mathias Wirth, Institut für Geschichte und Ethik der Medizin, Universitätsklinikum Hamburg-Eppendorf, Martinistr. 52, D-20246 Hamburg, E-Mail:m.wirth@uke.de 
where salvation is contingent on the "victim" forgiving their "tormenter", since God may not want to bring the "victim" eschatological peace without the "victim's” free decision. Menke's plea for an open history requires eschatological interactionism that demands the „victim's“ forgiveness. This was met with strong criticism from Bernd Oberdorfer in a controversy in 2009, who reminded of the possibility of finding it impossible to forgive. Oberdorfer points out two highly debatable assertions of Menke: firstly, that the "victim" notoriously remains a part of the "offender's" reckoning, and secondly, that the kingdom of God can only be reached if the last „victim“ pardons the „offender“. Menke’s votes for the model of uncertainty of salvation in eschatology ties the biblical vision of God "all in all” (1 Cor 15:28) to the fragility of human capabilities. The model of certainty of salvation in eschatology, which also features prominently in Christian theology, considers the new Heaven and the new Earth not a mere eventuality, but rather an imminent actuality. Here, Easter morning functions not as a utopia but as a symbol of hope that in no way assumes forgiveness of the unforgivable. Even the resurrected Christ did not reach out to his felons after his crucifixion. As life triumphs over death comes the beginning of something completely new that the "offender" and "victim" may wish for.

Keywords: Eschatological interactionism, Assurance of salvation, Infernalism, Offender-victim relationship, Reconciliation

Welche Hoffnung birgt das Christentum für alle, die auch „Opfer“ geworden sind? Hängt die Hoffnung auf universellen Frieden davon ab, dass jedes „Opfer“ seinem einstigen Peiniger die Hand zur Versöhnung reicht, wie Karl-Heinz Menke gegen die Intuition des Unverzeihlichen betont? ${ }^{1}$ Verlangt christliche Eschatologie von den unzähligen Opfern von Misshandlung und Mord allen Ernstes ein Shakehands mit den „Tätern“? Lässt der eschatologische Frieden unerbittlich auf sich warten, bis auch das letzte „Opfer“ das Widerwärtige verzeihen kann? Sind Konzessionen nötig, die gegen das Erleben des Grauens immer implizieren, dass es so schlimm ja nicht gewesen sei, denn wie sonst soll Verzeihen möglich sein, wenn nicht doch etwas Verzeihliches ausgemacht wird?² Droht der Freiheit der

1 Karl-Heinz Menke, Rechtfertigung: Gottes Handeln an uns ohne uns? Jüdisch perspektivierte Anfragen an einen binnenchristlichen Konsens, in: Cath(M) 63 (2009), 58-72, 70.

2 Damit ist keineswegs behauptet, beim Verzeihen handle es sich um eine Schrumpfform des Ethischen. Im Gegenteil, in vielen Fällen bildet das Verzeihen die „Mitte der Ethik“ (Klaus-Michael Kodalle) und erscheint als Schutz vor der Gefahr einer „Überforderung durch die Moral“ (Verena Rauen), vgl. Klaus-Michael KoDALLE, Verzeihung denken. Die verkannte Grundlage humaner 
„Opfer“ im eschaton das Versagen, nicht ansprechbar für das Unzumutbare eines ehrlichen Handschlags mit dem Peiniger zu sein? Müssen „Opfer“ und Angehörige je existentiell lernen, im konkreten Fall zwischen Täter und Tat zu unterscheiden $?^{3}$ Kennt christliche Hoffnung etwa nicht den Wunsch, am liebsten den Blick abzuwenden, um zu vergessen und neu zu beginnen? Bezeichnet die berühmte Zeile des Liedes Over the Rainbow aus Der Zauberer von $\mathrm{Oz}$, "Where trouble melts like lemon drops/ High above the chimney top/ That's where you'll find me“, nicht zu Recht das Bild der Hoffnung eines Neuanfangs, wo das Übel des Vergangenen wie geschmolzen ist?

Wäre die Frage nach einem Gottes alles in allem (1 Kor 15,28) und das Problem, wie dies angesichts pluriformer „Opfer“- und „Tätergeschichten“ möglich ist ${ }^{4}$, ob es mithin „Unversöhnbare Schuld“ oder ein „Recht auf Versöhnung“ gibt ${ }^{5}$, nicht so ernst, weil es um die Rechenschafft über die Hoffnung geht, die Christen erfüllt (1 Petr 3,15), dann wäre die dazu in erhöhtem Ton geführte Kontroverse zwischen den Systematikern Bernd Oberdorfer und Karl-Heinz Menke ein beinahe amüsantes Lehrstück. Weil es material aber um die „Abgeschmacktheit [einer] ganzen Fragestellung “6 geht, wie Oberdorfer notiert, der den Streit darüber aufnimmt, ob Menkes eschatologische Forderung einer Versöhnungsbereitschaft aller „Opfer“ nicht insgeheim eine Selbstverachtung der „Opfer“ animiere ${ }^{7}$, handelt der Disput von nicht weniger als dem Woraufhin christlicher Hoffnung.

Verhältnisse, München 2013, 9 und Verena Rauen, Rez. Kodalle: Verzeihung denken. Die verkannte Grundlage humaner Verhältnisse, München 2013, in: PhR 61 (2014), 242-244, 242. Zur Humanität des Verzeihens, besonders im Bezug auf Emmanuel Lévinas, vgl. Mathias WIRTh, Distanz des Gehorsams. Theorie, Ethik und Kritik einer Tugend (= Religion in Philosophy and Theology 87), Tübingen 2016, 271.

3 Jan-Heiner Tück, Unversöhnt in alle Ewigkeit? Hartmut Langes Novelle Das Konzert und die Hoffnung auf Versöhnung, in: Julia Knop/Magnus Lerch/Bernd J. Claret (Hg.), Die Wahrheit ist Person. Brennpunkte einer christologisch gewendeten Dogmatik (FS Karl-Heinz Menke), Regensburg 2015, 225-248, 246.

4 Marco HofHeinz, Terrorismusbekämpfung, Brudermord, Sündenbockmechanismus und Stellvertretungschristologie. Zur inspirierten Entdeckung versöhnungstheologischer Zusammenhänge - angeregt durch René Girard. Response zu Wolfgang Palaver, in: Wolfram WeißE (Hg.), Gewaltfreiheit und Gewalt in den Religionen, Münster 2015, 137-151, 137-140.

5 Siehe dazu das Forschungsprojekt von Maria WIRTH: http:kw1.uni-paderborn.de/institute-ein richtungen/institut-fuer-katholische-theologie/personal/wirth/lebenslauf/ [16.10.2015].

6 Bernd Oberdorfer, „Ohne uns“? Rhapsodische Anmerkungen zu Karl-Heinz Menkes Frontalangriff auf die lutherische Rechtfertigungslehre, in: Cath(M) 63 (2009), 73-80, 77 [Anm. 10].

7 Tück (s. o. Anm. 3), 245. Das Moment der Selbstverachtung besteht dabei besonders im Verlust von Differenz in der Versöhnung, vgl. Christoph Menke, Die Möglichkeit eines anderen Rechts. Zur Auseinandersetzung mit Andreas Fischer-Lescano, in: DZPhil 62 (2014), 136-143, 139. 
Die in 2009 geführte Debatte zwischen Oberdorfer und Menke ist an relevanten Stellen allerdings eher lakonisch ausgefallen, weshalb es einer theologischen Amplifikation bedarf. ${ }^{8}$ Mit Blick auf teilweise bisher bloß angedeutete oder ungenannte Problembezirke einer erheblich unter Druck geratenen These Menkes, soll sein leistungsaffines Modell eines eschatologischen Interaktionismus (axiologische Eschatologie) vor dem Hintergrund der eschatologischen Hoffnung auf ein innovatorisches Handeln Gottes (teleologische Eschatologie) im Folgenden gespiegelt werden. ${ }^{9}$

\section{Das Woraufhin eschatologischer Hoffnung - Konturen}

Der Streit zwischen Menke und Oberdorfer ist dem Konnex von Soteriologie und Eschatologie gewidmet und markierte einige kritische Punkte dieses Verhältnisses. Dieses Verhältnis mit dem Scharnier der notorischen Schuldhaftigkeit hat Jürgen Moltmann besonders pointiert, wenn er die Zukunft bei Gott auch als Überwindung des Schuldhaften beschreibt: „Auch in unserem Leben genügt es nicht, vergangene Schuld nur zu sühnen, um mit der Vergangenheit leben zu können, so wichtig das ist. Es muss etwas Neues geschaffen werden, so dass ,das Alte vergangen ist' (2 Kor 5,17), und man nicht aller Vergangenheit notorisch gedenken muss. ${ }^{10}$ Das ist mit der ,Auferstehung Christi von den Toten' gemeint: der Anfang der Neuschöpfung der Welt [...]." ${ }^{11}$ Das bedeutet aber auch: Egal, was

8 Die Dringlichkeit des Aufgreifens der Debatte ergibt sich aus der Wiederholung von Fehlern, die Oberdorfer bei Menke markiert, nun aber von Christiane Schubert repliziert wurden, vgl. Christiane Schubert, mere passive? Inszenierung eines Gesprächs über Gnade und Freiheit zwischen Eberhard Jüngel und Thomas Pröpper (= ratio fidei 55), Regensburg 2014, 16-26, 277279 und dazu Mathias Wirth, Rez. Schubert, Christiane, mere passive? Inszenierung eines Gesprächs über Gnade und Freiheit zwischen Eberhard Jüngel und Thomas Pröpper, in: ThPh 91 (2016), 149-152, 150-151. Die beinahe uneingeschränkte Parteinahme Schuberts für Menkes seltenes Votum hat natürlich höchstes Lob durch ihren spiritus rector erfahren, vgl. Karl-Heinz Menke, Das unterscheidend Christliche. Beiträge zur Bestimmung seiner Einzigkeit, Regensburg 2015, 153 [Anm. 291].

9 Hans Urs von Balthasar, Eschatologie in unserer Zeit. Die letzten Dinge des Menschen und das Christentum (= Studienausgabe), Einsiedeln/Freiburg 2008, 46.

10 Eberhard Jưngel, Außer sich. Theologische Texte, Stuttgart 2011, 26-27 und dazu Wirth (s.o. Anm. 2), 319.

11 Jürgen Moltmann, Gerechtigkeit für Opfer und Täter, in: Ders., In der Geschichte des dreieinigen Gottes. Beiträge zu einer trinitarischen Theologie, München 1991, 74-89, 85. Die an 2 Kor 5,17 orientierte Rede von der Neuschöpfung steht besonders aufgrund ihrer möglichen Nähe zu 
Menschen tun, um mit ihrer Schuld fertig zu werden, selbst Sühne und Vergebung machen das Übel des Geschehenen nicht einfach zu Nichtse. Vielmehr bedarf es eines Neuanfangs, der etwas ganz anderes sein muss als religiöser Eskapismus und schiere Zerstörung. ${ }^{12}$ Dieser Neuanfang bleibt Prärogativ Gottes ${ }^{13}$, der universellen Frieden in doppelter Hinsicht schafft, wenn Menschen sich in Freiheit für Gottes Angebot des Neuanfangs entschließen, den sowohl „Opfer“ als auch „Täter“ ersehnen können. Dabei irritiert Gottes Begriff der Gerechtigkeit seinen distributiven Charakter: „Gott ist gerecht, weil er rechtlosen Menschen Recht schafft und ungerechte Menschen zurechtbringt. Er schafft Recht denen, die Gewalt leiden, und er rettet durch seine Gerechtigkeit. Durch diese Gerechtigkeit

Konzepten der Ganztod-Theorie im Verdacht, zwar mit dem platonischen Dualismus aufgeräumt zu haben, mit der heraufbeschworenen Analogie von Ostern und creatio ex nihilo aber das Kind mit dem Bade auszuschütten, wenn damit jedes Kontinuitätsmoment genommen ist, vgl. Hartmut Rosenau, Vom Warten - Grundriss einer sapientialen Dogmatik. Neue Zugänge zur Gotteslehre, Christologie und Eschatologie (= Lehr- und Studienbücher zur Theologie 8), Münster/Berlin 2012, 199-199. Damit ist die Rede von einer Neuschöpfung aber keineswegs unbrauchbar und per se verdächtig, denn es sind ja Modi der Neuwerdung (creatio ex vetere [Polkinghorne und Moltmann] oder creatio ex creatione [Pöhlmann]) denkbar, die Momente des Vorigen integrieren und nicht einer völligen Vernichtung der Person bedürfen, vgl. John C. Polkinghorne, Reason and Reality. The Relationship between Science and Theology, Valley Forge 1991, 102-103; Horst Georg PöHLMANN, Abriss der Dogmatik, Gütersloh ${ }^{6} 2002,374$ und Robert J. Russell, Eschatology and Scientific Cosmology: From Deadlock to Interaction, in: Zygon 47 (2012), 991-1014, 1006. Eine in der neueren Theologie vertretene Variante der Kontinuitätswahrung bei größtmöglichem Neubeginn setzt auf Erinnerung, wobei es gerade Gottes anamnesis sei, die für Kontinuität des Menschen vor und nach seinem Tod sorge, vgl. zusammenfassend Friedrich Hermanni, Vom Winde verweht. Die christliche Hoffnung auf die Auferstehung der Toten, in: Peter Koslowski/Ders. (Hg.), Endangst und Erlösung, Bd. 1, München 2009, 139-159, 156. Aber auch Konzepte einer Restauration können Diskontinuitäten und Kontinuitäten gleichermaßen implizieren und versöhnen, im besten Fall Herkunft und Zukunft, vgl. Peter Kossowsкi, Vollendung der Geschichte als Restauration. Endangst, Zukunftsangst und Zukunftsglaube, in: Ders./Friedrich Hermanni (Hg.), Endangst und Erlösung, Bd. 1, München 2009, 205-221, 215-216.220-221 und Markus Mühling, The Eschatical Perfection of the World in God, in: IJST 12 (2011), 204-220, 205-206; wie auch die Vorstellung einer Wiedergeburt aus dem Heiligen Geist (Joh 3,5), die theologischerseits zu Unrecht in Misskredit geraten ist, vgl. Marco HofHeinz, Wiedergeburt? Erwägungen zur dogmatischen Revision eines diskreditierten Begriffs, in: ZThK 109 (2012), 46-67.

12 Günter Tномаs, Gottes schöpferische Neuzuwendung. Konturen und Konsequenzen des Umbaus eschatologischer Grundmodelle, in: Christoph Böttigheimer/Ralf Dziewas/Martin HaILER (Hg.), Was dürfen wir hoffen? Eschatologie in ökumenischer Verantwortung (= Beihefte zur Ökumenischen Rundschau 94), Leipzig 2014, 179-201, 189.

13 Christof Gestrich, Die Seele des Menschen und die Hoffnung der Christen. Evangelische Eschatologie vor der Erneuerung, Frankfurt a. M. 2009, 194. 
schafft Gott [...] gemeinsamen Frieden [...].“14 Keine Heldentat der Selbstverachtung schafft diese Gerechtigkeit als Bedingung für einen Frieden, der keineswegs den Unterschied zwischen „Opfern“ und „Tätern“ nivelliert, denn bei Moltmann erhalten „Opfer“ Recht und „Täter“ werden „zurechtgebracht“. Eine so proportionierte Eschatologie steht gegen eine forensisch orientierte Logik und gegen die traditionelle Vorstellung von einem dualistischen Geschichtsausgang, der - wie unten bei Menke zu finden - den Hiat zwischen „Tätern“ und „Opfern“ in Ewigkeit verschärft. Wenn man nicht die Notwendigkeit eines freien Einstimmens übersieht, dann bleibt die Möglichkeit eines Neins gegenüber der zurechtbringenden Gnade Gottes virulent. Neue eschatologische Entwürfe setzen auf die schöpferische Kraft Gottes ${ }^{15}$, dessen Nähe, Präsenz und Werben gerade nicht das Ende von Freiheit bedeuten. ${ }^{16}$ So kommt jedenfalls nicht der Verdacht auf, der gegen die apokatastasis-Lehre ${ }^{17}$ und eine vermeintlich billige, geschichtsnihilistische

14 Moltmann (s.o. Anm. 11), 88. Vgl. auch Peter Koslowski, Erlösung, Rechtfertigung, Satisfaktion des Gläubigers und Schuldenerlass. Philosophische Annäherungen an Vergeltung, Vergebung, Verschuldung und die Antinomie zwischen Erlösung aller und Höllenstrafe, in: Ders. (Hg.), Endangst und Erlösung, Bd. 2, München 2012, 83-119, 95. Bemerkenswert ist, dass dem Begriff der Gerechtigkeit Gottes im gesamten Ersten Testament die Komponente der Strafe fehlt, vgl. Gerhard von RaD, Theologie des Alten Testaments, Bd. 1, München ${ }^{4} 1962,389$ und dazu Christian Link, Wie kommt es zum „eschatologischen Dual“? Anmerkungen zum Problem der Allerlösung, in: Ruth HEß/Martin LeINER (Hg.), Alles in allem. Eschatologische Anstöße, Neukirchen-Vluyn 2005, 185-197, 196.

15 Siehe ebd., 179, der hinzufügt, eschatologische Gerichtsvorstellungen böten die Möglichkeit für Gott, „kreativ-schöpferisch“ auf die „Risiken seiner Schöpfung“ zu antworten, vgl. Tномаs (s. o. Anm. 12), 109.

16 Magdalene L. FRETTLÖH, Leben aus der Hoffnung auf die Zurechtbringung aller. Notizen zu Schuld und Vergebung, Sühne und Strafvollzug in eschatologischer Perspektive, in: EvTh 74 (2014), 364-379, 376.

17 Christian DAnz, „Und sie werden hingehen. Diese zur ewigen Strafe, aber die Gerechten in das ewige Leben“ (Mt 25,46). Überlegungen zur Funktion und Bedeutung des Letzten Gerichtes in der protestantischen Theologie, in: NZSTh 53 (2011), 71-89, 71-72.83-84. Johanna Christine Janowski hat mit ihrem eschatologischen Vorstoß zu einer „entdualisierten Eschatologie“ einen gewichtigen Beitrag zur Diskussion der Allversöhnungslehre (apokatastasis) geleistet, vgl. Johanna Christine Janowski, Allerlösung. Annäherungen an eine endualisierte Eschatologie, Bd. 1 u. 2, Neukirchen-Vluyn 2000 sowie Johanna Christine JANowsкi, Warum sollte Gott nicht alle erlösen?, in: Magdalene L. FretrlöH (Hg.), Gott wahr nehmen (FS Christian Link), Neukirchen-Vluyn 2003, 277-328, 277-328 und dazu Danz (s. o. Anm. 17), 82; Magdalene L. FrettlöH, „Ja den Namen, den wir geben, schreib’ ich ins Lebensbuch zum Leben“. Zur Bedeutung der biblischen Metapher vom „Buch des Lebens“ für eine entdualisierte Eschatologie, in: Ruth HEß/Martin LeInER (Hg.), Alles in allem. Eschatologische Anstöße, Neukirchen-Vluyn 2005, 133-165, 134 und Link (s. o. Anm. 14), 186. Michael Beintker hat an die Confessio Augustana und ihren Teil XVII erinnert, die einen doppelten Ausgang der Geschichte erklärt, vgl. Michael BEINTKER, Gottes Urteil über unser Leben. Das Jüngste Gericht als Stunde der Wahrheit, in: ZThK 110 (2013), 219-233, 229: „Bei dieser 
Gnade besteht ${ }^{18}$, denn personale Zukunft bleibt undenkbar, wenn es sich dabei um einen plumpen Automatismus handelt.

\section{Die Kontroverse zwischen Karl-Heinz Menke und Bernd Oberdorfer}

Als eschatologische Konsequenz wirksamer Anerkennung der Freiheit und Andersheit des Menschen ${ }^{19}$ durch Gott hat Karl-Heinz Menke mehrfach ein Szenario zum Skopus einer dicht an Thomas Pröpper angelehnten Freiheitsanalyse ${ }^{20}$ stilisiert, bei dem Erlösung an die Bedingung eines Verzeihungsaktes des „Opfers“ gegenüber seinem „Peiniger“ gebunden ist, weil Gott nicht am „Opfer“ vorbei eschatologischen Frieden kreieren könne. Schon vor seiner hier in Rede stehenden Ausführung zur Rechtfertigungslehre, die Oberdorfers theologische Hutschnur hat platzen lassen, hat Menke seine spezielle Auffassung zur Versöhnungslehre im Zusammenhang mit dem Versuch einer jüdisch inspirierten Christologie bereits thematisiert: „Sollte Christus je alles in allem und in allem sein, dann haben die „Opfer“ von Auschwitz freiwillig den Tätern die Hand gereicht und die Täter von Auschwitz Christi Liebe nicht nur passiv angenommen, sondern auch aktiv in die unendlich langen Wege der Umkehrung ihrer Sünde in die Sohnschaft inkarniert.“21 Abgesehen von Menkes betont „unendlich langen Wegen der Umkehrung“, die nahelegen, dass es nie zu universaler Versöhnung

Auffassung ist die evangelische Theologie freilich nicht stehen geblieben. [...] Im neuzeitlichen Protestantismus kam es bei namhaften Theologen zu der Vorstellung, dass Gott am Ende keinen Menschen vom eschatologischen Heil ausschließen werde.“

18 Vgl. ebd., 221; Koslowski (s. o. Anm. 14), 101-102 und Link (s. o. Anm. 14), 186.

19 Falk Wagner, Religion und Gottesgedanke. Philosophisch-theologische Beiträge zur Kritik und Begründung der Religion, Frankfurt a.M. 1996, 240-241. Dazu auch WirTh (s. o. Anm. 2), 322-233 und Mathias WIRTH, Was bedeutet: Unbedingte Anerkennung der Andersheit des Anderen? Intersexualität und Transidentität im Licht advokatorischer Ethik, in: Maximilian Sсносноw/ Saskia Gehrmann/Florian Steger (Hg.), Inter* und Trans ${ }^{\star}$ identitäten: Ethische, soziale und juristische Aspekte (= Beiträge zur Sexualforschung), Gießen 2016, 105-133, 113-127.

20 Mathias Wirth, Absurdität, Solidarität und Sinn. Albert Camus und die Freiheitsanalyse Thomas Pröppers, in: ThPh 89 (2014), 534-550, 542-546.

21 Karl-Heinz Menke, Jesus Christus - ,Wiederholung oder ,Bestimmung“ der Heilsgeschichte Israels? Zwei Grundgestalten jüdisch perspektivierter Christologie, in: Helmut HopING/Jan-Heiner Tück (Hg.), Streitfall Christologie. Vergewisserungen nach der Schoah (= QD 214), Freiburg/ Basel/Wien 2005, 125-158, 148. An anderer Stelle spricht er abgewandelt von einem „Umleiden der Sünde in Sohnschaft“, vgl. Menke (s.o. Anm. Anm. 8), 155. Vgl. dazu auch Tưck (s.o. Anm. 3), 246. 
kommen wird, zumal das schwer goutierbare Diktum von der „Umkehrung“ von Sünden durch „Inkarnation“ in „Sohnschaft“ nicht mehr ist als ein rhetorischer Ausflucht ins Prätentiöse, der allenfalls für fromme Ohren verschleiert, dass der eschatologische Friede Prärogative Gottes ist, so imponiert als intrikates Problem Menkes Konditionalisierung eschatologischen Friedens. Denn mit seinem Plädoyer für eine offene Geschichte redet er einem eschatologischen Interaktionismus das Wort, der dem „Opfer“ noch die Leistung abverlangt, verzeihen zu müssen. ${ }^{22}$ Zugleich wird so aber der mit Ostern begonnene Sieg über den Tod als Hoffnung auf ein Leben in endgültigem Frieden (adventus) völlig zweifelhaft und an die Fragilität menschlichen Vermögens gebunden (futurum): „Die Illusion der Selbstmächtigkeit, wie sie bei Menke [...] begegnet, traut der Versöhnungskraft Gottes zu einem neuen Anfang letztlich nicht alles zu; ängstlich wird hier Erlösung doch wieder an die Tat der Versöhnung des Menschen gebunden“. ${ }^{23}$

Unter II.1 soll Menkes Anmeldung von Zweifeln an der Konsensfähigkeit der Konsenserklärung kursorisch dargestellt werden. Die These von der eschatologischen Not-Wendigkeit aktiver Vergebung durch die Opfer, die Menke in besagtem Beitrag an eine Kritik der Gemeinsamen Erklärung gekoppelt hat, unterzieht Oberdorfer einer ebenso konfrontativen Inspektion, die unter II.2 rekonstruiert wird. Es folgt unter II.3 die Replik Menkes, die Oberdorfer unbeantwortet gelassen hat:

\section{II.1 Menkes bedingungsreiche Eschatologie}

Die Schärfung des theologischen Bewusstseins durch die Verbrechen des Nationalsozialismus, so beginnt Menke seinen Beitrag Rechtfertigung: Gottes Handeln an uns ohne uns? Jüdisch perspektivierte Anfragen an einen binnenchristlichen Konsens $^{24}$, hat die Theologie des 20. Jahrhunderts zu fundamentalen Neuakzentuierungen und Revisionen animiert. Gleichwohl, so Menke, sei es gerade die Soteriologie, die davon unberührt scheint (58). Gerade die Doktrin reinen Empfangens (mere passive) evoziere ein unsägliches Vergessen aller „Opfer“25, sodass

22 Wirth (s. o. Anm. 8), 151.

23 Ebd.

24 Erschienen in: Catholica. Vierteljahrsschrift für ökumenische Theologie 63 (2009). Die im Folgenden unter Punkt II.1 in Klammern gesetzten Seitenzahlen beziehen sich auf diesen Text Menkes. Eine Kurzfassung dieser Abhandlung findet sich in MenKe (s. o. Anm. 8), 152-155.

25 Diese Gefahr hat auch Jürgen Moltmann gesehen, allerdings mit Blick auf die theologische Prämisse der sola-gratia-Doktrin, die Annahme der Universalität der Schuld (Röm 3,23), vgl. Moltmann (s.o. Anm. 11), 75: „Die Schwäche des universalen Sündenbegriffs der paulinischlutherischen Rechtfertigungslehre liegt darin, dass die universale Kollektivschuld für konkrete 
gerade die Geschichte der Verfolgung der Juden im Nationalsozialismus die evangelische Gnadenlehre als Hohn gegenüber allen „Opfern“ enttarne (60). Insofern bedürfe Rechtfertigung zuvor eines aktiven, interexistentiellen Aktes der Versöhnung: „Oder kann einer der Täter von Auschwitz ,richtig“ (gerechtfertigt) sein vor Gott, wenn seine Opfer ihm nicht vergeben können? Und umgekehrt: Kann eines der Opfer von Auschwitz ,richtig، (gerechtfertigt) sein vor Gott, solange es ihm auf ehrliche Weise unmöglich ist, seinen Henkern wirklich zu vergeben?“ (61) Um es gleich vorwegzusagen: Genau an diesem Punkt entzündet sich später Oberdorfers scharfes Verdikt, weil ihm insbesondere die letzte Frage unerträglich erscheint, weil Menke dem „Opfer“ abverlangt, das ex parte homines Unentschuldbare zu vergeben. Von der Konzeption einer Versöhnung durch radikale, aber identitätswahrende Neuschaffung (wie bei Eberhard Jüngel ${ }^{26}$ oder Jürgen Moltmann ${ }^{27}$ ) hält Menke indes gar nichts und meint, der Protestantismus handle sich ein logisches Paradox ein, da eine Art Neukonstitution des Menschen im sola-gratia-Modell nichts erkennen lasse, was erhaltenswert sei (63). Sein Gegenprogramm besteht in der klassischen Annahme eines Reinigungsortes (Purgatorium) und einer doppelten Freiwilligkeit, an die Gott sein „alles in allem“ knüpfe. Die erste von Menke vorausgesetzte Freiwilligkeit bezieht sich auf die Täter, die, damit Gott einmal „alles in allem“ sei, im Angesicht Christi ihr maliziöses Tun dadurch abstreifen können (,sich mit dem Gericht gegen die eigene Sünde zu verbünden“), als sie, so Menke allen Ernstes, „[...] freiwillig durchlitten haben, was sie ihren Opfern angetan haben“ (64).$^{28}$ Es stellt sich aber sogleich die kritische Frage: Was soll diese Potenzierung von Leid (Infernalismus) ${ }^{29}$, die Gott

Schuld blind macht [...]. Die Universalität der Sünde führt in die Nacht, in der alle Katzen grau sind [...].

26 Eberhard JünGEL, Das Sein Jesu Christi als Ereignis der Versöhnung Gottes mit einer gottlosen Welt: Die Hingabe des Gekreuzigten, in: Ders., Entsprechungen: Gott - Wahrheit - Mensch. Theologische Erörterungen, München 1986, 276-284, 276-280.

27 Moltmann (s. o. Anm. 11), 78-81.

28 Menke (s. o. Anm. 8), 154. Anders als Menkes Vergeltungsszenario begnügen sich etablierte Eschatologien in der Regel damit, zwar auch von einer Art brennender Liebe im Purgatorium auszugehen, jedoch ohne die Annahme, das dabei eine Art Vergeltung stattfinde, wie Menke insinuiert. Stattdessen werde im Angesicht der Liebe Gottes die eigene Lieblosigkeit so bewusst, dass es zu einer Transformation der Person komme. Jedenfalls schließt die Begegnung mit der Liebe Christi völlig aus, was Menke annimmt: Das Täterinnen und Täter nun an der eigenen Haut erfahren, was sie verbrochen haben.

29 Giorgio Agamben, Was von Auschwitz bleibt. Das Archiv und der Zeuge, Frankfurt a. M. 2003 [Originaltitel Quel che resta di Auschwitz. L'archivio e il testimone], 87 und dazu Susan Neiman, Das Böse denken. Eine andere Geschichte der Philosophie, Frankfurt a.M. 2004 [Originaltitel Evil in Modern Thought. An Alternative History of Philosophy], 386. 
zu einem Ungeheuer machen würde? ${ }^{30}$ Menkes Antwort: Nur so könnte den Tätern, den nunmehr (durch das Feuer der Liebe Christi?) auch Misshandelten, Missbrauchten und Getöteten, menschlicherseits überhaupt verziehen werden, womit die zweite von Menke als conditio sine quo non gesetzte Freiwilligkeit bezeichnet ist, an die Gott die Vollendung der Welt bindet. Diese Freiwilligkeit meint die der „Opfer“, die einerseits niemals zur Verzeihung gezwungen werden können ${ }^{31}$, andererseits das Gott „alles in allem“ verhindern können. Menke durchschaut die bittere Konsequenz seiner Konzeption illusionslos, wenn er die damit einhergehende Offenheit der Geschichte betont, was ihm später den Vorwurf eingehandelt hat, er betreibe eine trostlose Eschatologie: „Es gehört [...] zum Wesen der Gnade des Erlösers, nicht nur die freie Zustimmung oder Ablehnung ihres Adressaten zu ermöglichen, sondern sich auch selbst von den Folgen der Zustimmung oder Ablehnung bestimmen zu lassen - falls nötig bis $\mathrm{zu}$ einem Geschichtsverlauf, der die Hoffnung Gottes, nämlich die universale Versöhnung, nicht erfüllt.“ (64). ${ }^{32}$ Menke plädiert so für ein tertium non datur, also gegen die Option hoffender Einwilligung in das exklusive Handeln Gottes. ${ }^{33}$ Ein Neubeginn, der etwas anderes ist als eine billige und unzulässige Gleichsetzung von Gut und Böse, „Tätern“ und „Opfern“, verlangt aber die freiwillige Einstimmung in die Passivität eines solus Christus. Eine solche Passivität meint Menke katholischerseits gänzlich verwerfen zu müssen. Daher bindet er Erlösung in seiner Konzeption an Leistung, prekärer Weise auch und gerade die der „Opfer“: „Nur unter Voraussetzung der freiwilligen Inklusion aller Opfer in die Selbstverschenkung Christi ist auch die Versöhnung zwischen Opfern und Tätern möglich“ (70). Schließlich betont Menke den für das Judentum und Christentum konstitutiven Nexus zwischen Rechtfertigung (Versöhnung mit Gott) und Ethik (Versöhnung mit dem Nächsten) und behauptet: „Es gibt im Christentum ebenso wenig wie im Judentum eine Versöhnung des Sünders mit Gott an der Versöhnung zwischen Tätern und Opfern vorbei“ (69). Dabei lässt er außer acht, dass es gerade das katholische Sakrament der Beichte ist, dass die Option einer Versöhnung mit Gott

30 Im Anschluss an Hans Blumenberg siehe Martin Zerrath, Vollendung und Neuzeit. Transformation der Eschatologie bei Blumenberg und Hirsch (= Marburger Theologische Studien 108), Leipzig 2011, 118.

31 Christoph SeIBERT, Versprechen und Verzeihen. Zwei Grundbegriffe unseres ethischen Selbstverständnisses, in: ZThK 109 (2012), 70-95, 87.

32 Menke (s. o. Anm. 8), 154.

33 Gunther Wenz, Von den letzten Dingen. Eschatologische Perspektive, in: KuD 61 (2015), 362386, 381. Auch in eschatologischem Zusammenhang erinnert Jan-Heiner Tück an ein Diktum Max Horkheimers, in dem das hier Gemeinte kulminiert, wenn er von der „Sehnsucht nach dem ganz Anderen“ spricht, vgl. Max Horкheimer, Die Sehnsucht nach dem ganz Anderen. Ein Interview mit Kommentar von Helmut Gumnior, Hamburg 1970, 61-62. Dazu Tưck (s. o. Anm. 3), 242. 
am „Opfer“ vorbei ganz ausdrücklich kennt ${ }^{34}$; die binnenkatholische Inkonsistenz seines ganzen Ansatzes, die er hier nolens volens dokumentiert, wird unten näher aufgegriffen.

\section{II.2 Oberdorfers Hinweise auf unhaltbare Konsequenzen}

In Oberdorfers theologischer enquête des Beitrags Menkes mit dem Titel „Ohne uns"? Rhapsodische Anmerkungen zu Karl-Heinz Menkes Frontalangriff auf die lutherische Rechtfertigungslehre ${ }^{35}$, moniert er insbesondere ein von Menke völlig verkanntes und verstelltes lutherisches Rechtfertigungsverständnis (73). Oberdorfers Erwiderung auf Menkes Kritik gliedert sich in sechs Aspekte: (I.) Insgesamt, so Oberdorfer, ventiliere Menke die altbekannten Vorwürfe des Katholizismus' gegen die Rechtfertigungslehre reformatorischer Provenienz, die mit der Gemeinsamen Erklärung in einen Konsens überführt werden sollten, nun aber durch Menke, entgegen dem Gros der Theologen, doch wieder eine Infragestellung erfahren, wenn er alte Zurückweisungen diesmal mit Rekurs auf das Verhältnis von Judentum und Christentum nicht nur wiederholt, sondern versucht neu $\mathrm{zu}$ fundieren (74). (II.) Auch der Sinngehalt des lutherisch-soteriologischen mere passive werde von Menke völlig missverstanden, denn damit sei keineswegs gemeint, Gott handle am Menschen „wie an einem toten Stein“ (ebd.). Vielmehr haben die Reformatoren damit die Abkehr von einer Facon gnadentheologischer Einseitigkeit intendiert, die unter dem Sammelbegriff Konditionssoteriologie subsumiert werden kann. Illusionslos hatten sie durchschaut, dass der unerbittliche Index der Endlichkeit, unter dem alles irdische Leben steht, den Menschen zum gänzlich ungeeigneten Akteur für ein Heil im Modus der Endgültigkeit macht. Wenn Gottes Handeln zum Heil des Menschen bedingungslos (sola gratia) erfolgt, dann bestehe der Skopus dieser theologischen Analytik nicht in einer Art Depersonalisierung, wie sie Menke unterstellt, sondern gerade in einer Entlastung endlicher Freiheit, die ersehnt, was sie nie selber zu leisten vermag. So bezweifelt Oberdorfer die systematische Konsistenz der Behauptung Menkes, die Passivität des Menschen im Gnadengeschehen bedeute zugleich existentielle Irrelevanz für den gerade nicht zum bloßen Objekt degradierten Empfänger von Gnade. Denn diese sei gerade nicht irgendetwas, sondern als in Vollendung begriffene Initiation eines neuen und guten Lebens für den je Einzelnen gedacht (ebd.). (III.) Rein

34 Wirth (s. o. Anm. 8), 150.

35 Erschienen in: Catholica. Vierteljahrsschrift für ökumenische Theologie 63 (2009). Die im Folgenden unter Punkt II.2 in Klammern gesetzten Seitenzahlen beziehen sich auf diesen Text Oberdorfers. 
assertorisch gerate dann Menkes Urteil über die ethischen Konsequenzen der lutherischen Rechtfertigungslehre, das bloß das „überholte Klischee“ (75) von der privatistischen Verkürzung und der Intransigenz gegenüber der Not der Anderen bediene. Nun ist gar nicht zu bestreiten, dass damit eine oft vermutete Inklination der reformatorischen Soteriologie benannt ist, nur ist diese Präjudiz längst entkräftet, wie Oberdorfer unter Rekurs auf Luthers Von der Freiheit eines Christenmenschen aus 1520 betont. Darin erscheine nämlich der reine Geschenk-Charakter der Gnade nicht als Terminierung, sondern umgekehrt, geradezu als Ermöglichung der Hinwendung zur Not des Anderen ${ }^{36}$ : „Weil mir von Gott meine Sünde vergeben und alles Heilsnotwendige geschenkt ist, muss ich mich nicht mehr um mich selber sorgen, sondern kann mich dankbar und in einem präzisen Sinn selbstlos für andere einsetzen.“ (ebd.). Theologischer common sense sei doch inzwischen, die Substitution eines gnadentheologischen Imperativs durch einen Indikativ der Gnade nicht für den Ausfall eines ethischen Imperativs zu halten. ${ }^{37}$ Das Gegenteil ist der Fall, weil das Prärogativ des Angenommenseins in einem eminenten Sinn zur Annahme des Anderen führt. ${ }^{38}$ (IV.) In der Eschatologie werde nach Oberdorfer die unzumutbare Konsequenz des Ansatzes Menkes besonders deutlich. Denn aus der Passivitäts-Zurückweisung folgt die bittere Notwendigkeit, dass „Opfer“ ihren Peinigern verzeihen müssen. Oberdorfer hält gerade diese Bedingung für eine theologische „Ungeheuerlichkeit“ (76). Gerade an diesem Punkt macht Oberdorfer deutlich, dass aus mehreren Gründen eben nur eine reine Passivität des Menschen um des Menschen selbst willen angenommen werden darf. Dabei zeigt sich, wie unattraktiv Menkes harsche Zurückweisung des mere passive ausfällt, weil sie kein Bild liefert, in dem sich der hoffende Menschen wiederfindet. Wenn also die novissima bei Menke an die aktive Versöhnungstat aller „Opfer“ gebunden sind, dann besteht zunächst das Problem darin erklären zu müssen, wie alles erlittene Unrecht, jeder Mord, jede Misshandlung, jede brutale Ausgrenzung, die Leben irreversibel geschädigt hat, menschlicherseits vergeben werden kann. Dies aber muss um der „Opfer“ willen bezweifelt werden. Oberdorfer erinnert an die Option der Unmöglichkeit des Verzeihens und an die Taktlosigkeit des Ansinnens Menkes, der die „Opfer“ nicht ihrem oft verständli-

36 Vgl. WA 7, 20-38.

37 Wolfgang Huber, Folgen christlicher Freiheit. Ethik und Theorie der Kirche im Horizont der Barmer Theologischen Erklärung, Neukirchen-Vluyn ${ }^{2} 1985,16$ und WIRTH (s. o. Anm. 2), 340.

38 Dies lässt sich auch psychologisch validieren: Die Bereitschaft, etwas zu leisten, ist dann höher, wenn Akteuren mit einer umfassenden Benevolenz (Rechtfertigung) begegnet wird und gerade nicht mit einer sanktionsreichen Moral des Imperativs. Echtes Engagement folgt nicht der Logik des direktiven Sollens. 
chen Wunsch nachkommen lässt, einfach den Blick abzuwenden. ${ }^{39}$ Bei Menke, so Oberdorfer, bleibe das „Opfer“ notorisch Teil der Rechnung des Täters, der am Ende ein nihil obstat verlangt, wenn es der Mensch und nicht Gott ist, der einen neuen Anfang schafft (76). Oberdorfer verleiht seiner Sprachlosigkeit über diese theologische Dreistigkeit, die die Zukunft an die Leistung des „Opfers“ bindet, um so die Dysbalance zwischen „Opfer“ und „Täter“ abermals zu substantiieren, dadurch Ausdruck, als er fragt, ob das wirklich Menkes Ernst sei. Der Ökumeniker Oberdorfer hat aber keine Zweifel, dass Menke hier etwas vertrete, was keinesfalls dem römisch-katholischen Konsens entspreche $(76-77)^{40}$. (V.) Dass gerade Shakehands-Konditionalisierung eschatischer Hoffnung aus seiner so apostrophierten „jüdisch perspektivierten Anfrage“ erwächst, erscheint Oberdorfer angesichts des Hasses, den gerade jüdische Opfer des Nationalsozialismus nicht selten mit letalen Konsequenzen durchleiden mussten, als reiner Zynismus. Wie kommt Menke dazu, fragt Oberdorfer empört, genau $\mathrm{zu}$ wissen, was die „Opfer von Auschwitz“ in der Versöhnungsfrage genau wollen oder nicht wollen? Letztlich instrumentalisiere Menke sie zu Opfern schlechthin (77); um so übrigens sein tatsächliches Desinteresse an einem jüdisch-christlichen Dialog zu dokumentieren, der schon gescheitert ist, wenn eine Pflicht zur Versöhnung im Raum steht.

Schließlich ist es nicht so, als spreche rein gar nichts für die Insistenz Menkes auf der Unhintergehbarkeit von Freiheit, allerdings, so Oberdorfer, bedeute es nicht gleich eine „Enteignung des menschlichen Selbst“ (79 [Anm. 18]), wenn man mitkonzipiert, dass wir nicht immer aktive Subjekte sind und es auch nicht gleich das Versagen einer Freiheit bedeutet, wenn sie sich etwas schenken lässt. Dies lässt sich gegen die Konsequenzen aus Menkes Versuch einer wirksamen Anerkennung von Freiheit aufrufen, denn eschatologisch folgt letztlich das glatte Gegenteil und die Denunziation christlicher Hoffnung, wie Oberdorfer abschließend pointiert herausstellt, da Menkes Option „eines Geschichtsverlaufs, der die Hoffnung Gottes, nämlich die universale Versöhnung, nicht erfüllt"“41 endlicher Freiheit abverlangt, woran sie nur scheitern kann und was ihr zu Lebzeiten nie

39 Jüngel (s. o. Anm. 10), 26-27. In soteriologischer Absicht fragt Hartmut von Sass, ob es nicht auch in Gott ein Vergessen (annihilatio memoriae) geben müsse, weil anders Vergebung und ein soteriologischer Neuanfang undenkbar seien, vgl. Harmut von SAss, Vergeben und Vergessen. Über eine vernachlässigte Dimension der Soteriologie, in: NZSTh 44 (2013), 314-343, 318.

40 Dieser Einschätzung Oberdorfers zur allgemeinen katholischen Verbindung von Soteriologie und Eschatologie entspricht auch Jeffrey Gros, Hope for Eternal Life: The Lutheran-Catholic Dialogue, in: J. E. S. 46 (2011), 259-269, 259.

41 Menke (s. o. Anm. 1), 64. 
gelang: sich selbst von den Verstrickungen, Brüchen, Unfähigkeiten und Ohnmächten zu erlösen (ebd.). ${ }^{42}$

\section{II.3 Menkes Verdikt gegen ein Verdikt?}

In seiner ebenfalls noch im selben Jahrgang der Catholica erschienenen Antwort Argumente statt Verdikte. Eine kurze Replik auf Oberdorfers ,rhapsodische Anmerkungen " ${ }^{\text {433 }}$ betont Menke bereits im ersten Satz, Oberdorfer habe überhaupt keine theologischen Gründe, sondern lediglich scharfe Verdikte vorgetragen (138); womit Menke zugleich konzediert, dass seinerseits eine argumentative Auseinandersetzung im Grunde unnötig sei. ${ }^{44} \mathrm{Er}$ kommt aber dennoch einigen geforderten, explanatorischen Verpflichtung nach.

Zunächst wiederholt Menke seine Sorge um die Freiheit des gerechtfertigten Menschen und liest aus der Antwort Oberdorfers heraus, nicht nur die Rechtfertigung, sondern auch deren Annahme erfolge an der Freiheit des Menschen vorbei und verunmögliche mithin Negation, folglich rede Oberdorfer einer Apokatastasislehre das Wort (138-139). Abermals betont Menke den Zusammenhang von Rechtfertigungsgeschehen und Ethik und bleibt trotz der erhobenen Bedenken dabei, dass die Rechtfertigung erst wirklich vollzogen sei, wenn Taten folgten (139), sonst, so Menke, ganz im Duktus der alten Werkgerechtigkeit, sei der Glaube „billig“ und „desinkarniert“ (140). Menke hält überdies daran fest, dass es einer Degradierung zum Objekt gleichkomme, wenn Gott am Menschen so handelt, dass der Mensch dabei reines Empfangen ist.

Wenn Menke in seiner Replik betont, Paulus spreche gar nicht von einer Gewissheit, sondern bloß von einer eher vagen Hoffnung auf einen Gott alles in allem $^{45}$, dann stellt sich die Frage - um es gleich vorweg zu nehmen - wie dies

42 Bernd Oberdorfer, Resakralisierung als Signum der Postmoderne? Chancen und Gefahren für den Frieden, in: Ders./Peter Waldmann (Hg.), Die Ambivalenz des Religiösen. Religion als Friedensstifter und Gewalterzeuger, Freiburg i. Br./Berlin/Wien 2008, 377-394, 382-383.

43 Erschienen in: Catholica. Vierteljahrsschrift für ökumenische Theologie 63 (2009). Die im Folgenden unter Punkt II.3 in Klammern gesetzten Seitenzahlen beziehen sich auf diesen Text Menkes.

44 Dies zeigt auch die Tatsache, dass Menke seine Thesen zum eschatologischen Interaktionismus ganz unverändert in 2015 wieder anführt, ohne dabei irgendwelche Konzessionen nach dem Gespräch mit Oberdorfer zu machen, vgl. Menke (s. o. Anm. 8), 152-155.

45 Diese Einschätzung Menkes hält allerdings kaum einer exegetischen Untersuchung stand. Eine Analytik relevanter Teile der Paulusbriefe belegt sehr deutlich das glatte Gegenteil, vgl. Hans-Christian Kammler, Der Trost des Evangeliums angesichts des Todes. Biblisch-theologische Perspektiven, in: KuD 61 (2015), 48-69, 63: „So sehr der Tod auch nach Ostern noch immer die 
neutestamentlich und mit Blick auf die Reich-Gottes-Reden und ihre präsentische Eschatologie $\mathrm{zu}$ verstehen ist, die doch wohl verbindet, dass sie von einer Dialektik des Schon und Noch-Nicht ausgehen, mithin den Beginn der Herrschaft Gottes als definitiv und gewiss im Werden auffassen (z. B. Lk 17,21: „[...] das Reich Gottes ist in eurer Mitte" $)^{46}$ und Christus als Garant dieser Entwicklung erscheint (z. B. Joh 11,25: „[...] ich bin die Auferstehung und das Leben“). ${ }^{47}$ Als universale concretum ist er keine Ausnahme, sondern exemplarischer Mensch. ${ }^{48}$

Wenn Menke der lutherischen Rechtfertigungslehre vorwirft, ihre Eschatologie strebe im Grunde einer völligen Ersetzung des alten durch einen neuen Menschen zu (Ganztod-Theologie ${ }^{49}$ ), so meint er in Oberdorfer einen Exponenten dieser eschatologischen Figur gefunden $\mathrm{zu}$ haben $(141)^{50}$; obwohl Oberdorfer das kurz zuvor expressis verbis problematisiert hat und daran erinnert, dass es

Macht hat, unsere Nächsten von uns zu trennen, so wenig hat er nun noch die Macht, sie von Gott $\mathrm{zu}$ trennen. Diese positive Gewissheit zieht sich [...] wie ein Leitmotiv durch die Schriften des Neuen Testamentes hindurch.“ Unter Verweis auf „,...] so wird Gott auch die, die entschlafen sind, durch Jesus mit ihm zusammenführen“ (1 Thess 4,14) und „Ich bin fest davon überzeugt, dass weder Tod noch Leben [...], weder Höhe noch Tiefe noch irgendein anderes Geschöpf uns trennen kann von der Liebe Gottes“ (Röm 8,38) wird also mehr als offensichtlich, dass Paulus keineswegs, wie Menke ihm unterstellt, eschatologischem Zweifel zuspricht.

46 Beintker (s.o. Anm. 17), 223; Marco Hofheinz, Wie neue Menschen leben. Ansätze zu einer Ethik der Identität im Heidelberger Katechismus, in: Martin Ernst Hirzel/Frank MAthwig/Matthias Zeindler (Hg.), Der Heidelberger Katechismus als reformierter Schlüsseltext, Reformiert! Bd. 1, Zürich 2013, 145-172, 160-164; Rosenau (s.o. Anm. 11), 195 und weiter Gestrich (s.o. Anm. 13), 114-116.202. Dann aber ist zu fragen, ob Betonungen in der Eschatologie, die einen Hoffnungsbegriff im Gegenüber zu einem Gewissheitsbegriffs favorisieren, überhaupt ernst machen mit der präsentischen Dimension der „Transformation der alten Welt“, vgl. Link (s.o. Anm. 14), 193.

47 KAMmler (s. o. Anm. 45), 61.

48 Vgl. ebd. 62.

49 Rosenau (s. o. Anm. 11), 198-199. Johannes Calvin hingegen hatte Ganztod-Vorstellungen noch als „viehische[n] Irrtum“ verdammt, vgl. Hermanni (s. o. Anm. 11), 146-147, der hier aus Calvins Institutio Christianae Religionis (1536) zitiert.

50 Menke (s. o. Anm. 8), 105. Ein Blick in Luthers Thesenreihe Disputatio de homine (1536), vgl. Gerhard Ebeling, Lutherstudien, Bd. II (Disputatio de homine), Tübingen 1977, 23, deutet allerdings in eine andere Richtung. Zwar wird man aus heutiger Sicht die Problematizität der Rede vom Menschen als Stoff (,pura materia“) herausstellen, wobei damit die reine Passivität des Menschen im Erlösungsgeschehen gemeint ist und keine Herabwürdigung des Menschen, vgl. Zerrath (s. o. Anm. 30), 2 und weiter Gestrich (s. o. Anm. 13), 199 [Anm. 26]. Deutlich wird aber, dass Luther hier keine völlige Ersetzung des alten durch den neuen Menschen intendiert, vielmehr im Modell der Wiederherstellung und Vollendung argumentiert. Es wird deutlich, die Vorstellung einer annihilatio mundi und des Menschen ergibt sich nicht aus dem Denken Luthers, sondern entspringt der theologischen Spekulation altprotestantischer Dogmatik, vgl. ZerRATh (s.o. Anm. 30), 2 [Anm. 5]. 
zwischen den beiden Extremen, völlige Kontinuität und völlige Diskontinuität zwischen dem Leben vor und nach dem Tod, doch wohl Zwischenvarianten gäbe. ${ }^{51}$

Es folgt dann ein sich über mehr als eine Seite hinziehendes Zitat aus einer Enzyklika Joseph Ratzingers, mit dem Menke seine Replik beschließt, die an entscheidender Stelle allerdings Menkes Votum für einen eschatologischen Interaktionismus kassiert, wenn in der Enzyklika Spe Salvi die Rede von einer Heilung ist, die die Seelen erführen und reif machten für die Gemeinschaft mit Gott. ${ }^{52}$ Damit ist deutlich die Option eines rein passiven Empfangens von Heilung und Reinigung am „Opfer“ vorbei mitkonzipiert - übrigens auch post mortem - entgegen Menkes Absage an Lebensrevisionen nach dem Tod (141). ${ }^{53}$ Ob Menke glaubt mit dem Herbeirufen einer Enzyklika einen protestantischen Theologen überzeugen zu können? Bezeichnender Weise hat Oberdorfer jedenfalls die Stellungnahme Menkes unkommentiert gelassen.

\section{Unerledigte Aspekte des Dogmatiker-Streits}

\section{III.1 Pauschaler Opferbegriff}

Was Menkes freiwillige, aber gleichwohl notwendige Shakehands-Forderung zwischen „Tätern“ und „Opfern“ betrifft, fallen zunächst intrikate phänomenologische Probleme auf, die Oberdorfer in seiner Replik auf Menke kurz angeführt hat. Da ist zunächst ein viel zu pauschaler Opferbegriff, der sich anheischig macht, individuelle Widerfahrnisse gewaltsam zu stilisieren. Damit eng verbunden ist das Problem der Komplexität sozialer und moralischer Verhältnisse, die Menkes dichotomer Trennung von Täter- und Opfer-Gruppe nur ephemere Validität verleihen. ${ }^{54}$ Eine Analytik des Bösen kommt schnell auf das Phänomen anonymer

51 Gestrich (s. o. Anm. 13), 115 und dann besonders Oberdorfer (s. o. Anm. 42), 388.

52 Vgl. Joseph Ratzinger, Auf Hoffnung hin gerettet. Die Enzyklika Spe Salvi, Freiburg i. Br. 2007, Nr. 45: „Und endlich fehlt nicht der Gedanke, dass es in diesem Zustand auch Reinigung und Heilung geben kann, die die Seele reif machen für die Gemeinschaft mit Gott.“

53 Diese Absage Menkes ist übrigens umso unverständlicher, als er zuvor noch das „Fegefeuer“ als Instanz der Reinigung eingeführt hat. Wer aber dem Purgatorium, so wie Menke, konstitutiv transformativ-transmissiven Charakter zuweist, der etabliert eben doch einen postmortalen Ort mit der Option zur Revision des Lebensskripts, vgl. Danz (s. o. Anm. 17), 72. Es ist daher unsinnig, wenn Menke zuvor sowohl von einem ausbleibenden Optionsraum nach dem Tod als auch vom Purgatorium spricht, wiederholt er so doch bloß die Doppelzüngigkeit der katholischen Dogmatik in dieser Angelegenheit.

54 Тномаs (s. o. Anm. 12), 195-196 und Jean-Claude Wolf, Das Böse, Berlin/Boston 2011, 1. 
Schuld, wobei sich keiner finden will, der den „Opfern“ die Hand zur Versöhnung reicht. ${ }^{55}$ Schließlich überziehen $\mathrm{zu}$ einfache Urteile das Konto menschlicher Erkenntniskraft, wie Luther festhielt, als er Gott den einzig angemessenen Richter nannte. Diese epistemische Intransparenz hat Peter Koslowski mit Blick auf den Reformator besonders gewürdigt: „Nur Gott kann uns gerecht beurteilen, rechtfertigen und richten. Nicht aber vermögen wir selbst oder unsere Mitmenschen ein im letzten gerechtes Urteil über uns $\mathrm{zu}$ fällen. Diese Einsicht Luthers ist schlechthin philosophisch und theologisch einleuchtend. “56

\section{III.2 Verwirrter Bundes-Begriff}

Menkes Betonung der Notwendigkeit einer eschatologischen Versöhnung von „Täter“ und „Opfern“ gründet außerdem auf der Verwirrung von formaler und materialer Dimension des Bundes. Menke rückt nur die Beziehung der Bundespartner ins Blickfeld und übersieht dabei den Worumwillen des Bundes. Statt Befreiung durch Gott als Schaffung eines neuen Anfangs zum Skopus des Bundeshandelns Adonais zu erklären, bleibt Menke, im Anschluss an seinen Gewährsmann Helmut Merklein, bei den Modi dieses Bundes, die keineswegs trivial sind, verhindert so aber eine adäquate Sicht auf die Materialität des Bundes als Befreiungsgeschehen. Auch wenn man zugibt, dass Gottes Bundeshandeln Heil und Erlösung nicht an der Freiheit des Menschen vorbei durchsetzt, so gerät eine Bundestheologie zu kurz, die das innovatorische Handeln des partnerschaftlichen Bundes-Gottes übersieht. ${ }^{57}$ Will man der bereits angeführten Oster-ExodusAnalogie weiter folgen, erscheint darin Gott allein und in allen Phasen als Initiator eines Neuanfangs ohne Geschichtsverlust. Weder im Exodus noch im analogen Ostergeschehen ist die Befreiung aus der maliziösen Macht des Pharaos, bzw. des Todes an eine Aufarbeitung gebunden; die Exodus-Gruppe muss den Peinigern nicht erst noch verzeihen, bevor sie in das gelobte Land aufbrechen dürfen.

55 Moltmann (s.o. Anm. 11), 86 und Wirth (s.o. Anm. 8), 151. Ähnlich komplexe Verhältnisse hat wohl auch Jan-Heiner Tück im Blick, wenn er festhält, vgl. Tưck (s. o. Anm. 3), 225: „Vieles, was in der Geschichte geschieht und Menschen auseinanderreißt, Beziehungen zerrüttet, kann in der Geschichte nicht mehr geklärt, aufgearbeitet und geheilt werden.“

56 Koslowski (s. o. Anm. 14), 92.

57 Vgl. ebd. 173 und Von Balthasar (s. o. Anm. 9), 48. 


\section{III.3 Unterbestimmung des eschatologischen novum- Charakters}

Gravitationszentrum christlicher Eschatologie ist die Hoffnung auf Gottes innovatorisches, und das heißt eschatologisches Handeln als Schaffung eines neuen Himmels und einer neuen Erde (Offb 21,1). ${ }^{58}$ Besagtes Anderes und Neues sind dabei von zentraler Bedeutung, weil sie alleine denkbar machen, dass trotz menschlicher Unendschuldbarkeit Gott alles in allem (1 Kor 15,28) sein kann. Auch unter dieser eschatologischen Perspektive werden Wunden nicht einfach verschwinden ${ }^{59}$; Jesu Wundmahle fungieren als Wiedererkennungsmerkmale und sind nicht einfach ausgesöhnt. ${ }^{60}$ Aber sie sind verklärt, das heißt aufgehoben in einen neuen Himmel und eine neue Erde. ${ }^{61}$ Nur so werden aus Opfergeschichten keine „Erinnerungshöllen“ und aus Tätergeschichten keine „Ohnmachtshöllen““ ${ }^{62}$ Menkes Bestehen auf einer für das Eintreffen des Reiches Gottes unaussetzbaren Aussöhnung zwischen „Tätern“ und „Opfern“ macht die Erinnerung an das Übel zum neuralgischen Punkt und kreiert gerade so Höllen der Erinnerung und Ohnmacht.

Keineswegs erscheint eine Theologie des Neuanfangs im eschaton analogie$\operatorname{los}^{63}$, denn alltagspsychologisch lässt sich ausweisen, dass eine gewisse Zeit, manchmal nur die eine berühmter Nacht, Dinge neu- oder anders proportioniert, sodass zwar eine Beleidigung oder Verletzung nicht plötzlich gut erscheint, aber sie kann nicht mehr sonderlich relevant wirken und eine trauernde Retrospektive aufheben. Wer einen Menschen lange nicht gesehen hat, mit dem er oder sie eigentlich noch eine Rechnung offen hat, der braucht für das gelingende Gespräch nicht unbedingt eine Aussöhnung. Obwohl der Peiniger von damals vor einem steht, ist doch etwas Neues geworden, ohne dass das Alte schlicht untergegangen wäre. Denkbar ist also eine Versöhnung zwischen „Täter“ und „Opfer“, ohne dass das Unverzeihliche vergeben werden muss.

Die bereits angeführte Rede vom radikalen Neuen aus der Offenbarung des Johannes etabliert außerdem eine Zukunft, die allein als Prärogative Gottes

58 Gunther Wenz, Vom apostolischen Osterzeugnis. Notizen zu Gedanken Hans-Georg Geyers, in: Dietrich KoRsch/Hartmut Ruddies (Hg.), Wahrheit und Versöhnung. Theologische und philosophische Beiträge zur Gotteslehre, Gütersloh 1989, 167-189, 180 und KAMmLER (s. o. Anm. 45), 60.

59 Tномаs (s. o. Anm. 12), 197-198.

60 Link (s. o. Anm. 14), 187.

61 Tück (s.o. Anm. 3), 244.

62 Тномаs (s. o. Anm. 12), 201.

63 Wenz (s. o. Anm. 58), 174. 
erscheint $^{64}$, denn im Jesus-Apophthegma „Siehe, ich mache alles neu“ (Offb 21,5) wird das zukünftige Rettungshandeln gerade nicht als Leistung, auch nicht als kongeniales Mithandeln des Menschen bestimmt. ${ }^{65}$ Nicht allein aufgrund der Bedrohung all dessen, was Menschen beginnen ${ }^{66}$, auch die Erfahrung des Zwiespalts von Wollen und Vollbringen und die Erfahrungen von Versagen und Schuld mit ihrer mehr als anekdotischen Evidenz ${ }^{67}$, verweisen die Hoffnung auf einen Frieden, den Menschen selbst nicht hervorbringen können und auf eine Zukunft, die nicht machbar ist. ${ }^{68}$ Deshalb ist der „Tag des Herrn“, um ein Wort von Michael Beintker aufzugreifen, eben kein von Menschen selbst zu bewerkstelligender „Versöhnungstermin“.69 In diesem Zusammenhang hat sich in der Theologie der Gebrauch der Termini adventus und futurum etabliert, wobei ersterer Begriff die Zukunft des unverfügbaren Ankommens Gottes in der Zeit meint und Letzterer menschliches Potential. ${ }^{70}$ Als genuiner Hoffnungsbegriff firmiert dabei die Zukunft des adventus, der nach Ulrich H. J. Körtner darin bestünde, dass Menschen und Welt neue Möglichkeiten erhielten, keineswegs also überwunden würden oder selber leisten müssten, was sie befreit. ${ }^{71}$

\section{III.4 Ostern nicht ein für alle mal?}

Komponente des Ostergeschehens ist Befreiung, die zwar das Vergangene nicht im Modus der Amnesie einfach vergessen lässt, aber nach Art der Verwandlung

64 Moltmann (s. o. Anm. 11), 82 und weiter Gestrich (s. o. Anm. 13), 105.

65 Kammler (s. o. Anm. 45), 60 und Ulrich H. J. Körtner, Zukunft als radikal Neues. Theologie und Kirche müssen sich stärker mit der Apokalyptik auseinandersetzen, in: Zeitzeichen 13/11 (2012), 33-35, 35.

66 Mathias Wirth, „Wasch ab meine Schuld, von meinen Sünden mache mich rein“. Zur bleibenden Mythologie von Hygiene und Waschung, in: Hans Werner Ingensiep/Walter PopP (Hg.), Hygieneaufklärung im Spannungsfeld zwischen Medizin und Gesellschaft (= Lebenswissenschaften im Dialog 23), Freiburg/München 2016, 273-306, 290.

67 Mathias Wirth, Es lebe die Erbsünde?! Schnittstellen zwischen Degenerationstheorie und Erbsündendoktrin, in: Eva Brinkschulte/Mariacarla Gadebusch-Bondio (Hg.), Norm als Zwang, Pflicht oder Traum. Normierende versus individualisierende Bestrebungen in der Medizin (FS Heinz-Peter Schmiedebach), Frankfurt a. M. 2015, 79-102, 83-85.

68 Von Balthasar (s.o. Anm. 9), 29. Allgemeiner gewendet: Hoffnung ist eben jenes, das nicht durch eigenes Tun garantiert werden kann, vgl. Christoph Menke, Grenzen der Gleichheit. Neutralität und Politik im Politischen Liberalismus, in: DZPhil 50 (2002), 897-906, 902.

69 BeintKer (s. o. Anm. 17), 228.

70 Jürgen Moltmann, Das Kommen Gottes. Christliche Eschatologie, Gütersloh 1995, 43-44. Und weiter Kammler (s. o. Anm. 45), 48 und Russell (s. o. Anm. 11), 1004.

71 Körnter (s. o. Anm. 65), 35. 
und nicht des Locked-In-Syndroms funktioniert und sowohl ein Kontinuitäts- als auch ein fulminantes novum-Moment impliziert: „[...] das Ostergeschehen [...] befreit [...] diese Erinnerung, ohne sie substantiell zu komplementieren, aus trauernder Retrospektive, indem es das Vergänglichkeitsgesetz des alten Äons aufhebt [...]“. ${ }^{72}$ Was Gunther Wenz hier in christologischer Perspektive als Gehalt des Osterereignisses entfaltet, erscheint zugleich als Hinweis auf die Denkbarkeit eines österlichen Neuanfangs, ohne ein depersonalisierendes Untergehen des Vergangenen. ${ }^{73}$

Im Zusammenhang mit einer Theologie, die das Ostergeschehen reflektiert, lässt Menke also völlig außer acht, dass Sünde, Tod und Unversöhnlichkeit im Begriff des Verschwindens $\operatorname{sind}^{74}$, Hans Urs von Balthasar spricht sogar von einem „Ein für allemal“ der Auferstehung Jesu. ${ }^{75}$ Es scheint überdies Grundanliegen aller Religionen, das Böse nicht für eine ultimative Realität zu halten. ${ }^{76}$ Der Illegitimitätsvorwurf gegen den eschatologischen Interaktionismus und die stets mit gesagte Option des Scheiterns der endlichen Freiheit und mithin des Reiches Gottes findet in dieser Optik auch interreligiöse Grundierung, wenn dort ein Konsens über die fehlende Persistenz des Übels und des Leidens besteht. Bei Licht besehen behauptet Menke die Option der „Endlosigkeit der Sünde“ und supponiert einen theologischerseits unhaltbaren Dualismus, der das Nein mit dem Ja ontisch und theologisch gleichsetzt. Dabei verkennt und verstellt er das Fundament christlicher Hoffnung, denn „Christliche Zeugenschaft kann, darf und soll [...] getrost davon ausgehen und dessen gewiss sein, dass der Gott, der den

72 Wenz (s.o. Anm. 58), 171. Vgl. Moltmann (s.o. Anm. 11), 80. Das hier zum Ausdruck kommende Bedürfnis, einmal zu vergessen, hat Hans Blumenberg als wichtige Pointe der Eschatologie hervorgehoben, vgl. Hans BlumenBERG, Unveröffentlichtes (zitiert bei ZerRath (s. o. Anm. 30), 116): „Ich behaupte: Es ist immer ein Bedarf an Weltuntergang da. Er besteht im Verlangen nach Entlastungen, das jeder hat, der mit seinem Leben nicht fertig wird oder zu werden glaubt, der die konstitutiven Enttäuschungen der Lebenserfahrung nicht zu deren ,Realismus‘ aufzuarbeiten imstande war."

73 Moltmann (s.o. Anm. 11), 80.

74 Wenz (s. o. Anm. 58), 179. Ähnlich hat dies auch Peter Koslowski für das Phänomen des Bösen nuanciert, vgl. Peter KosLowski, The Origin and Overcoming of Evil and Suffering in the World Religions. Introduction, in: Ders. (Hg), The Origin and Overcoming of Evil and Suffering in the World Religions, Dordrecht 1986, 1-7, 2: "God guarantees by his absoluteness that evil and suffering are not likewise absolute, that they have not always existed and will not exist for all eternity." Anders bliebe auch die österliche Rede vom Christus als dem Erstgeborenen von utopischer Natur, vgl. Moltmann (s. o. Anm. 11), 79.

75 Von Balthasar (s. o. Anm. 9), 45. Von Balthasar ordnet seine Beobachtung zum Richtungssinn der Zeit im Anschluss an Eph 5,16 dem Terrain christlicher Gewissheit zu, vgl. ebd. 46.

76 Koslowski (s. o. Anm. 74), 5. 
Gekreuzigten auferweckt hat, seine in Jesus Christus offenbare Wahrheit in der Kraft des Geistes auch fernerhin bewähren wird“".77

Menke betreibt dagegen eine regelrechte Aushöhlung des eschatischen Horizontes genuin christlicher Hoffnung ${ }^{78}$, so zutreffend seine Bemerkungen über die wirksame Anerkennung menschlicher Freiheit durch das Bundeshandeln Gottes auch sind. Seine Insistenz auf einem aktionistischen Versöhungsgeschehen, das die Breche im Horizont nicht anders denkt als durch eine Begegnung zwischen „Täter“ und „Opfer“ und damit die Option einer fundamentalen Neuwerdung, trotz des breiten biblischen Zeugnisses, etwa über den neuen Morgen etc., nicht einmal erwägt, bedrängt nun selbst die Freiheit der „Opfer“. Ausdrücklich hat nämlich Elie Wiesel, selbst ein Opfer nationalsozialistischer Verbrechen, gefordert: „Denen, die für diese Verbrechen verantwortlich sind, darf nicht verziehen werden ". ${ }^{79}$ Der Morgen von Ostern verlangt das auch nicht. Der auferstandene Gekreuzigte reicht seinen Schächern nicht die Hand. Im Sieg des Lebens über den Tod beginnt ein neues Äon, das etwas anderes ist als die Versöhnung des Unversöhnlichen. Jean Améry, ein weiterer Überlebender der KZs, hat genau dies erhofft, einen Zustand

77 WenZ (s. o. Anm. 58), 186.

78 Beintker (s.o. Anm. 17), 220.

79 Jorge Seprún/Elie Wiesel, Schweigen ist unmöglich, Frankfurt a.M. 1997, 35-36. Vgl. Neiman (s. o. Anm. 29), 383-384. Christoph Seibert erinnert allerdings an Hanna Arendt und ihre Unterscheidung zweier Modi der Vergebung. Arendt schlage nämlich vor, einer Person zu verziehen, niemals aber die monströse Tat selbst zu vergeben. Auf diese Weise sei auch ein „neuer Anfang“ möglich, vgl. Seibert (s. o. Anm. 31), 85-86 und, ebenfalls zu Arendts Begriff der Verzeihung in theologischer Absicht, FRETtLöH (s.o. Anm. 16), 365-367. Allerdings betont Frettlöh in ihrer Arendt-Lese anders als Seibert, dass es bei Arendt nicht um die Vergebung des Bewussten gehe, sondern nur um das unabsichtlich begangene Böse, das „schuldlose Schuldigwerden“, vgl. ebd. 365-366. In diesem Zusammenhang erinnert Frettlöh an Jacques Derrida, besonders an den „Gabe-Charakter“ der Vergebung, ohne den sie unwirklich sei, vgl. Jacques DerRIDA, Eine gewisse unmögliche Möglichkeit, vom Ereignis zu sprechen (= Internationale Merve-Diskurse 254), übers. v. Susanne Lúdemann, Berlin 2003, 29: „Wenn ich nur vergebe, was sich vergeben lässt, vergebe ich nichts. [...] Wenn ich nur vergebe, was lässlich ist, das heißt entschuldbar, verzeihlich, ein geringer Verstoß, eine begrenzte und messbare Schuld in einer begrenzten Angelegenheit, dann vergebe ich nichts. [...] Ich kann also, wenn ich vergebe, nur das vergeben, wo es Unverzeihliches gibt. Da, wo Vergebung unmöglich ist.“ Vgl. auch FrETtLÖH (s. o. Anm. 16), 365. Seine Eingabe meint aber nicht, schlechthin alles müsse verziehen werden, wenn er betont, nur dann kann überhaupt von Verzeihung die Rede sein, wenn es sich um Unverzeihliches handelt. Diese prägnante Interpretation kann also keineswegs für die eschatologische und universelle Versöhnungsnötigung Menkes in Anschlag gebracht werden, da Derrida den Ausnahme-Charakter der Vergebung als Gabe betont, vgl. Jacques DeRrida, Im Gespräch mit Michel Wieviorka, in: Lettre International 48 (2000), 10-18, 10: „Die Vergebung [...] sollte weder normal noch normativ noch normalisierend sein. Sie sollte Ausnahme und außergewöhnlich bleiben, als Erprobung des Unmöglichen.“ 
nämlich, in dem das Vergangene wie ungeschehen ist: „Was geschah, geschah: der Satz ist ebenso wahr wie er moral- und geistfeindlich ist. Sittliche Widerstandskraft enthält den Protest, die Revolte gegen das Wirkliche, das nur vernünftig ist, solange es moralisch ist. Der sittliche Mensch fordert Aufhebung der Zeit. “80 Der eschatologische Neuanfang bedeutet genau dies für „Opfer“ (und „Täter“) und ihren Wunsch, das Vergangene auszulöschen ${ }^{81}$ : sich nicht in Ignoranz, sondern gerade in Vigilanz gegenüber der Geschichte nach diesem Neuen sehnen und das Neue, ganz passiv und doch frei, geschehen zu lassen, weil nur Gott die angemessene Antwort auf das Unwiederbringliche ist. ${ }^{82}$ Das eben meint Ostern.

\section{III.5 Diskreditiertes „schon“ im „noch nicht“}

Theologische Konzepte einer offenen Geschichte, wie hier von Menke favorisiert, sind vor dem Ostergeschehen zu rechtfertigen. Zwar ist ebenso wenig plausibel, dass Gott als „Herr der Geschichte“ zur Zweitursache in der Welt wird und das Geschick der Welt wie des Einzelnen durch direkte Intervention manipuliert, denn: „Ein Gott, der in einem bloß kontingenten Rhythmus [etwa] Krankheit nimmt, ist ein grausamer Gott.“"83 Dennoch kann die Rede von Gott als „Herr der Geschichte“ nur um den Preis einer Hoffnung aufgegeben werden, nach der Gott schon im Begriff ist, ein definitiv gutes Ende zu sein. ${ }^{84}$ Theologische Entwürfe einer offenen Geschichte diskreditieren dies, wie Menke bei Thomas Pröpper gelernt hat, als Prädestination oder Vorsehung. ${ }^{85}$

80 Jean Améry, Jenseits von Schuld und Sühne, Stuttgart 1977, 116. Dazu auch Neiman (s.o. Anm. 29), 388.

81 Vgl. ebd. Virulent bleibt aber die Frage, wozu das Leben zuvor dann überhaupt gelebt werden muss. Die Intuition Menkes ist vor dieser Frage ja nachvollziehbar, nur zieht er falsche Konsequenzen. Zumal dann, wenn man das Leben als Zugehen Gottes auf den Menschen hin versteht, vgl. Ingolf U. Dalferth, Gott für uns. Die Bedeutung des christologischen Dogmas für die christliche Theologie, in: Ders./Johannes Fischer/Hans-Peter Großhans (Hg.), Denkwürdiges Geheimnis, Beiträge zur Gotteslehre, Tübingen 2004, 51-75, 75: „Die Welt ist der Lebensraum, in dem Gott die Abwendung der Menschen von ihm überwindet, indem er ihnen Zeit und Raum zum Leben mit ihm einräumt.“

82 Tномаs (s. o. Anm. 12), 130.

83 Wirth (s. o. Anm. 66), 299.

84 Körnter (s. o. Anm. 65), 35 und Moltmann (s. o. Anm. 11), 79.

85 Thomas PröPPER, Theologische Anthropologie. Erster Teilband, Freiburg i. Br. ${ }^{2} 2012,490$ : „Würden seine [Gottes] Prädestination und Vorsehung dagegen den Weltlauf im voraus festlegen, so wären dabei die Menschen nur Mittel, würde Geschichte zum Schicksal und Gottes Herrschaft zur Tyrannei.“ Die Diskussion um das Reizthema Prädestination ist endlos, deshalb soll nur ein Argument gegen den Vorwurf Pröppers genannt werden, wobei nicht einmal klar ist, ob seine 
Außerdem gerät Ostern in geschichtsoffenen Eschatologien zu einer bloßen Utopie, als sei Christus bloß ein Exponent der Auferstehung und nicht ihr Ermöglichungsgrund. ${ }^{86}$ Die bei Menke nur als Vision $\mathrm{zu}$ verstehende Ostergeschichte wird bei Licht besehen zur grausamen Vision, die ein höchst fragiles Hoffnungsbild transportiert, weil auch nur das eine „Opfer“ so gut zu verstehen wäre, dass das Unverzeihliche nicht vergeben kann: „Es gibt Unverzeihliches, wenn man Leid nicht verharmlost und Liebe, auch über Jahre und Jahrzehnte, nicht aufgibt." ${ }^{87}$ Menkes Vorstoß kann sich diese Sensibilität für das Opfer und seine Familie und Freunde, trotz aller pathetischen Anklänge, deshalb nicht leisten, weil sein finaler Shakehands-Aktionismus denkbar bleiben muss, will er nicht umstandslos einen endzeitlich-düsteren Ausgang der Geschichte annehmen. ${ }^{88}$

Hilflos ist Menkes Plädoyer für eine offene Geschichte außerdem gegenüber dem Einwand, dass gerade solche Konzepte die Freiheit, die sich achten wollen, in prekärer Weise gefährden: „Gegen die Beteuerung, das soteriologische Konzept einer offenen Geschichte mache ernst mit der Achtung menschlicher Freiheit, gerät der zum Opfer stilisierte Mensch [...] in die zynische Situation, seinem Peiniger verzeihen zu müssen, um nicht selbst Täter verwirkter Zukunft zu werden. Sind der ,neue Himmel und die neue Erde““ (Offb 21,1) nicht Resultat eines durch Gott gewirkten Neubeginns, der Freiheit ermöglicht und nicht vernichtet, dann stehen geschichtsoffene Konzepte [...] mindestens in der Gefahr, die Freiheit, die sie schützen wollen, in einem tragik-umwitterten Zynismus zu erledigen." 89

Rede von einer „unerschöpflichen Innovationsmacht“ Gottes oder seinem „unbedingten Heilswillen“ (ebd.) die Rede von einer offenen Geschichte zum theoretischen Postulat macht. Dieser Verdacht erhärtet sich umso mehr, als Pröpper an anderer Stelle einschärft, vgl. Thomas PRöPPER, Erlösungsglaube und Freiheitsgeschichte: eine Skizze zur Soteriologie, München ${ }^{3} 1991$, 29: ,[...] ein Glaube an Erlösung, der nicht zu trösten vermöchte, verdiente nicht seinen Namen." Redliche Vertreter offener Konzepte der Geschichte müssen sich allerdings jede Tröstung verbieten. Zweifelhaft bleibt aber insgesamt, ob Konzepte der Heilsgewissheit (s. Fazit) den Menschen zum bloßen Mittel, Geschichte zum reinen Schicksal und Gott zum Tyrannen machen. Vielmehr gilt doch der umgekehrte Fall, denn eine absolut offene Geschichte lässt den Menschen zum hoffnungslosen Spielball verkommen, dessen Geschichte ohne Verheißung auf einen Gott verweist, dem Leben und Welt nichts bedeuten. Wer trotz verfügbarer Mittel endliche Freiheit finaliter ins Verderben gehen lässt, ist zwar kein Paternalist, aber ein Killer.

86 Wenz (s. o. Anm. 33), 369 und Gestrich (s. o. Anm. 13), 202-203.

87 Wirth (s.o. Anm. 8), 151. Vgl. auch Neiman (s. o. Anm. 29), 389 und Von Sass (s. o. Anm. 39), 340.

88 Wirth (s. o. Anm. 8), 150.

89 Ebd. 151. 


\section{Das Woraufhin eschatologischer Hoffnung - Konkretionen}

Darin ist Menke zuzustimmen, dass es keinen Himmel geben kann, in dem auch nur ein Bruder oder eine Schwester fehlt; mit dem Unterschied, das dies bei Menke die Freiheit des Menschen durch Akte der universellen Versöhnung leisten muss. Bei Oberdorfer wird auf Gottes innovatorisch-eschatologisches Handeln gesetzt, das nicht völlig analogielos ist, weil an die zwischenmenschliche Erfahrung des neuen Morgens oder der tempi passati angeknüpft werden kann. ${ }^{90}$

Menkes Prinzipalisierung der direkten Täter-Opfer-Versöhnung führt in allen Fällen schweren Leids und großer Schuld zu einer Überforderung menschlicher Freiheit, die Unverzeihliches nicht einfach in einem selbstverachtenden Akt übergehen kann. ${ }^{91}$ Menkes entsprechende Forderung erweist sich dabei als „Illusion der Selbstmächtigkeit“. ${ }^{92}$ Wir sind nicht immer aktive Subjekte! Nichts anderes besagt das in manus tuas (Ps 31,6). ${ }^{93}$ Luthers Gegenmodell zum Fegefeuer, der Gedanke des Seelenschlafs, betont gerade die von Menke gänzlich in Abrede gestellte Option existentieller Bedeutung der Passivität. ${ }^{44}$ Vollendung ist schlicht

90 Genau dieses Phänomen der Neu-Proportionierung nach dem Vergehen der Zeit hat auch Emmanuel Lévinas im Sinn, wenn er Versöhnung als „Werk der Zeit“ versteht, vgl. Emmanuel LÉvinAs, Totalität und Unendlichkeit. Versuch über Exteriorität, Freiburg/München ${ }^{2} 1993,413$ und Emmanuel Lévinas, Jenseits des Seins und anders als Sein geschieht, Freiburg/München 1992, 261.325. Dazu auch Rauen (s. o. Anm. 2), 244.

91 Koslowski (s. o. Anm. 14), 109. Die fünfte Bitte des Vater unser (,wie auch wir vergeben unsern Schuldigern“) könnte gegen meine These und Kritik an Menke gelesen werden. Bei näherem Zusehen stellt sich aber heraus, wie wenig es in dieser Bitte um generelle Schuld oder gar Unverzeihliches geht. Vielmehr ist der turnusgemäße Erlass von Schulden gemeint ist, der in Dtn 15,1-2 gemäß der Sabbatlogik gefordert wird und als zentrales Gebot biblischer Wirtschaftsregeln gilt, vgl. FrETTLÖH (s. o. Anm. 16), 369-370. Auch dabei ist mitkonzipiert, dass es sich bei diesem Erlassen von monetären Schulden letztlich um Menschenunmögliches handelt, Adonai also Bedingung der Möglichkeit dieses Prinzips ist, vgl. ebd. 370 und weiter Magdalene L. FretrLöH, „Der Mensch heißt Mensch, weil er ...vergibt"? Philosophisch-politische und anthropologische Vergebungsdiskurse im Licht der fünften Vaterunserbitte, in: Jürgen Евасн (Hg.), Wie? Auch wir vergeben unsern Schuldigern? Mit Schuld leben, Gütersloh 2004, 179-215, 180-192.

92 Wirth (s.o. Anm. 8), 151.

93 Von Balthasar (s. o. Anm. 9), 34.

94 Hermanni (s.o. Anm. 11), 141. Natürlich ist dies nur eine Analogie, aber man käme auch nicht auf die Idee, das Ergebnis einer in Vollnarkose und mithin absoluter Passivität ertragenen Operation für existentiell irrelevant zu halten. Warum sollte feststehen, dass eine ohne das gänzliche Mitwirken des Menschen durch Gott vollzogene Erlösung, sein individuelles Einverständnis vorausgesetzt, keine Relevanz für das Individuum habe? 
nichts, was je in der Geschichte $\mathrm{zu}$ erreichen ist. ${ }^{95}$ Genau dies aber erwartet Menkes eschatologischer Interaktionismus vom zum „Opfer“ gewordenen Menschen, wenn Zukunft durch Versöhnungsbereitschaft restringiert wird.

Damit votiert Menke für das Modell der Heilsungewissheit in der Eschatologie, die bei ihm umso fulminanter ausfällt, als er das „alles in allem“ an die Fragilität dessen bindet, was Menschen vermögen. ${ }^{96}$ Das ebenfalls in der christlichen Theologie prominent vertretene Modell der Heilsgewissheit in der Eschatologie hält den neuen Himmel und die neue Erde nicht für eine bloße Eventualität, sondern für eine anbrechende Faktualität. ${ }^{97}$ Geht es im Denken eschatologischer Ungewissheit des Heils um die bange Frage, ob Gott das Herz der Menschen gewinnen wird, so leitet das Denken eschatologischer Heilsgewissheit die Frage, wie Gott das Herz des Menschen gewinnt. ${ }^{98}$

Weil der Begriff der Heilsgewissheit theologische Abwehrreflexe provoziert, soll zum Abschluss ein berühmter Exponent des Modells der eschatologischen Heilsgewissheit, Friedrich Schleiermacher, erinnert werden. ${ }^{99}$ Es genügt hier der exemplarische Hinweis auf den berühmten Brief Schleiermachers an die frühe Witwe Henriette von Willich, die er später heiraten wird, in dem er zwar sehr deutlich in Distanz zu den vielen kursierenden Bildern geht, die die eschatologische Zukunft viel zu plastisch ausschmücken. An dieser Zukunft selbst aber hegt er keinen Zweifel: „Gewissheit ist uns über dieses Leben hinaus nicht gegeben, verstehe mich recht, ich meine Gewissheit für die Phantasie, die Alles in bestimmten Bildern vor sich sehen will, aber sonst ist es die größte Gewissheit, und es wäre nichts gewiss, wenn es nicht das wäre, dass es keinen Tod gibt, keinen Untergang des Geistes."100 Weiter ermutigt Schleiermacher die trauernde Frau: „Aber lass in Deinem heiligen Schmerz Deine liebende Phantasie dichten nach allen Seiten hin und wehre ihr nicht."101

Wäre die Überwindung des mitunter gravierenden Hiats zwischen „Tätern“ und „Opfern“ Aufgabe menschlicher Freiheit, bliebe das Reich Gottes bloße Utopie; für Modelle eschatologischer Heilsgewissheit ein „kompletter Ausstieg

95 Koslowski (s. o. Anm. 11), 205 und Wirth (s. o. Anm. 2), 336.

96 WENZ (s. o. Anm. 33), 380.

97 Vgl. ebd. 366: „[...] auf Gottes in Jesus Christus manifeste Versöhnungsliebe [ist] Verlass und zwar definiter Verlass [...]. Am letzten Ende wird die Liebe Gottes alles in allem und in vollkommener Weise mit der göttlichen Gerechtigkeit eins sein. Wie das zugehen soll, wissen wir aus unserer Selbst- und Welterfahrung heraus mit hinreichender Bestimmtheit zu sagen."

98 Gestrich (s. o. Anm. 13), 193.

99 BeintKer (s. o. Anm. 17), 231.

100 Friedrich Daniel Ernst Schleiermacher, Aus Schleiermachers Leben. In Briefen, Bd. 2 (Brief an Henriette von Willich, 25. März 1807), Berlin 1958, 85-86.

101 Ebd. 
aus der christlichen Hoffnung “102, wie Christof Gestrich im Anschluss an Schleiermacher notiert: „Christliche Bilder vom Eschaton dürfen nicht die Heilsgewissheit des Glaubens angreifen oder aufweichen, sie müssen sich vielmehr in sie einordnen. Sie sollen nicht ,alles in der Schwebe lassen', sondern in dem Sinn ,Seelenbilder` sein, dass sie die Vollendung des Menschen im Reich Gottes thematisieren. “103 Entgegen der Gefahr eines „völligen Verlust[s] der Heilsgewissheit“104 steht die theologische Option der Gewissheit des schon angebrochenen Reiches Gottes, in dem eschatologische Neuschaffung alleiniger Grund für das Ende des Duals zwischen „Opfern“ und „Tätern“ ist.

102 Gestrich (s. o. Anm. 13), 191.

103 Ebd. In diesem Zusammenhang hat Christof Gestrich auch den Gewissheitscharakter des Glaubens sowie der Hoffnung pointiert, u. a. unter Rekurs auf Jes 7,9 [Anm. 7], wo Glaube definiert wird als Bezugnahme auf das Verlässliche, vgl. ebd. 193: „Glaube braucht nicht nur Gewissheit, sondern Glaube ist eine Form von Gewissheit. Denn Glaube bedeutet nichts anders als sich befestigen im Verlässlichen. [...] Auch Hoffnung ist nicht so etwas wie eine ,abgeschwächte Gewissheit ' [...], sondern sie ist der Arm, mit dem sich der Mensch nach dem Bleibenden austreckt. Beim Hoffen geht es um die Fundamente unserer Existenz“, wie Gestrich unter Verweis auf 1 Kor 13,13 (,Nun aber bleiben Glaube, Hoffnung und Liebe“) bemerkt, vgl. auch Mưhuing (s.o. Anm. 11), 209.

104 Gestrich (s. o. Anm. 13), 190. 